\title{
ACÚMULO E DISTRIBUIÇÃO DE BORO EM CULTIVARES DE ALGODÃO ${ }^{(1)}$
}

\author{
Ciro Antonio Rosolem ${ }^{(2)}$, Angélica Cristina Fernandes Deus ${ }^{(3)}$, Priscila Oliveira \\ Martins $^{(4)}$ \& Érica Pontes Léles ${ }^{(3)}$
}

\begin{abstract}
RESUMO
O algodoeiro é responsivo à adubação boratada, porém há poucas e controversas observações a respeito da mobilidade do nutriente dentro da planta. Este trabalho teve por objetivo avaliar a translocação e o acúmulo de boro (B) em cultivares de algodão. Quatro cultivares de algodão (FM 993, FM 910, FMT 701 e FMT 523) foram cultivadas em duas concentrações de B (0 e 4,5 mmol $\mathrm{L}^{-1}$ ) na solução nutritiva, em vasos com capacidade de $8 \mathrm{~L}$ preenchidos com areia lavada, por seis semanas. Os vasos receberam solução nutritiva uma vez por semana. Em seguida, as plantas foram amostradas durante quatro semanas consecutivas, determinando-se a matéria seca e acúmulo total de $B$ nas raízes e na parte aérea, a distribuição e acúmulo de $B$ nos tecidos da planta e o teor e acúmulo de $B$ nas folhas em diferentes nós da haste principal. $O$ delineamento experimental foi em blocos ao acaso, em esquema fatorial $4 \times 2$, com parcelas subdivididas no tempo (semanas de amostragem), com quatro repetições. As cultivares FM 993 e FMT 523 alcançaram maior produção de matéria seca e acúmulo de $B$ na raiz. Plantas cultivadas sem deficiência de $B$ acumulam mais de $50 \%$ do $B$ nas folhas, ao passo que, em plantas sem aplicação do micronutriente, o $B$ se encontra em maior proporção nas raízes e no caule. Não há evidência de translocação de B em diferentes cultivares de algodão, mesmo quando cultivadas em deficiência desse nutriente.
\end{abstract}

Termos de indexação: Gossypium hirsutum L., deficiência de boro, nutrição mineral, micronutriente.

(1) Recebido para publicação em 2 de maio de 2011 e aprovado em 15 de junho de 2012.

(2) Professor Titular do Departamento de Produção Vegetal, Faculdade de Ciências Agronômicas, Universidade Estadual Paulista, Campus de Botucatu. Rua José Barbosa de Barros, 1780, Caixa Postal 237, Botucatu (SP). CEP 18.610-307. Bolsista CNPq. Email: rosolem@fca.unesp.br

(3) Doutorandas em Agronomia, PPG Agricultura, Faculdade de Ciências Agronômicas, Universidade Estadual Paulista, Campus de Botucatu. E-mail: angeldeys@yahoo.com.br, ericapleles@yahoo.com.br

(4) Mestranda em Agronomia, PPG Agricultura, Faculdade de Ciências Agronômicas, Universidade Estadual Paulista, Campus de Botucatu. E-mail: pomartins@fca.unesp.br 


\title{
SUMMARY: BORON TRANSLOCATION AND ACCUMULATION INCOTTON CULTIVARS
}

\begin{abstract}
Cotton is responsive to boron fertilization, however, results on the mobility of this nutrient in the plant are few and controversial. This study had the objective of evaluating boron translocation and accumulation in cotton cultivars. Four cotton cultivars (FM 993, FM 910, FMT 701, and FMT 523) were grown for six weeks in 8 L pots with washed sand and nutrient solution at two boron concentrations ( 0 and $\left.4.5 \mu \mathrm{mol} \mathrm{L}{ }^{-1}\right)$. After six weeks, plants were sampled for four more weeks to determine dry matter yield and total boron accumulation in root and shoots, boron distribution in plant tissues, and boron content and accumulation in leaves from different plant nodes. The experiment was arranged in a $4 x 2$ factorial with sub plots (sampling time) and four replications. Dry matter yield and boron accumulation in roots were highest in the cultivars FM 993 and FMT 523. Cotton plants grown in non-deficient $B$ solutions accumulate more than $50 \%$ of the absorbed B in leaves, but in B deficient plants, B is found at a higher proportion in roots and stems. There is no evidence of $B$ translocation in different cotton cultivars, even in plants under $B$ deficiency.
\end{abstract}

Index terms: Gossypium hirsutum L., boron deficiency, mineral nutrition, micronutrient.

\section{INTRODUÇÃO}

$\mathrm{O}$ acúmulo de $\mathrm{B}$ em plantas está relacionado à quantidade de pectina na parede celular, e, uma vez que gramíneas contêm menos pectina, acumulam menos B do que dicotiledôneas (Blevins, 2009). Como dicotiledônea, o algodão tem exigência relativamente elevada de B (Zhao \& Oosterhuis, 2002), acumulando em média $340 \mathrm{~g} \mathrm{ha}^{-1}$ de $\mathrm{B}$ e exportando aproximadamente $12 \%$ do nutriente acumulado (Rochester, 2007). Distúrbios nutricionais causados pela deficiência de B em algodoeiro são bastante comuns em solos tropicais, onde a matéria orgânica do solo e, ou, teor de argila são baixos (Rosolem et al., 2001).

O boro é essencial à formação dos tecidos meristemáticos e tem influência no desenvolvimento de raízes e na absorção de nutrientes. Sua deficiência durante o florescimento do algodoeiro causa queda de frutos e reduz a produtividade e a qualidade da fibra (Carvalho et al., 2007). A deficiência de B em algodão, mesmo que temporária, leva à má formação dos vasos do xilema, o que pode diminuir a translocação de nutrientes e de carboidratos para novos tecidos (Oliveira et al., 2006). Sabe-se ainda que a deficiência de $B$ pode limitar significativamente a produtividade mesmo sem qualquer sintoma visível, caracterizando a ocorrência de "fome oculta" (Satya et al., 2009). Assim, a deficiência de boro não é facilmente reconhecida, mesmo na diagnose foliar, uma vez que as plantas de algodão com $11 \mathrm{mg} \mathrm{kg}^{-1}$ de $\mathrm{B}$ nas folhas mais recentemente maduras tiveram produção de matéria seca semelhante à de plantas não deficientes, embora o número de estruturas reprodutivas tenha sido menor (Rosolem et al., 1999).

O transporte do B ocorre no xilema, tendo sido considerado, por muito tempo, praticamente imóvel no floema. Entretanto, foi demonstrado que esse micronutriente é móvel no floema de algumas plantas, como: macieira, ameixeira, cerejeira e brócolis (Brown \& Shelp, 1997). A mobilidade do B no floema é possível quando o nutriente se liga a compostos que apresentam a configuração cis-diol (itóis), formados durante o processo fotossintético e transportados pelo floema (Loescher et al., 1995). Acredita-se que no algodoeiro não ocorra a formação desses itóis, ou ocorra em quantidade insuficiente. Assim, se existe mobilidade desse elemento nessa cultura, ela é bastante limitada (Rosolem \& Costa, 2000). Contudo, mais recentemente, evidências se acumulam sugerindo que mesmo plantas que não produzam açúcares-álcoois podem apresentar algum transporte de B no floema, principalmente para tecidos jovens (Tanaka \& Fugiwara, 2008). Essa translocação foi observada em condições de fornecimento limitado de B, mas não em suprimento normal do nutriente. Ainda, elaborou-se a hipótese de que canais iônicos estariam envolvidos nesse tipo de transporte. $O$ fato de o transporte ocorrer somente em condições de deficiência sugere que as plantas seriam capazes de reagir ao baixo suprimento e regular o transporte de B (Tanaka \& Fujiwara, 2008).

A seleção de cultivares eficientes na utilização e capazes de translocar B pode prevenir quedas na produtividade, sobretudo em situações nas quais a aplicação de fertilizantes de B é dificultada (Rerkasem, 2002) ou mesmo quando ocorre deficiência temporária do nutriente, como foi demonstrado por Rosolem \& Costa (2000). No Brasil, foi observado que cultivares de algodão mostraram eficiências distintas de utilização de $\mathrm{B}$, respondendo diferencialmente à sua adição ao solo (Fontes et al., 2008). No entanto, poucos são os estudos a respeito da translocação desse nutriente em algodoeiro, tornando-se importante compreender o caminhamento de $\mathrm{B}$ nos tecidos vegetais durante o crescimento da planta. O objetivo deste trabalho foi avaliar a translocação e o acúmulo de $\mathrm{B}$ em cultivares de algodão. 


\section{MATERIAL E MÉTODOS}

O experimento foi realizado em casa de vegetação na Faculdade de Ciências Agronômicas, UNESP, Botucatu/SP. Os tratamentos consistiram de quatro cultivares de algodão de ciclos diferentes, entre as mais cultivadas no Brasil (FM 993 - ciclo médio/tardio, FM 910 - ciclo médio, FMT 701 - ciclo médio tardio e FMT 523 - precoce), duas doses de B $\left(0\right.$ e $\left.4,5 \mu \mathrm{mol} \mathrm{L}^{-1}\right) \mathrm{e}$ quatro avaliações (realizadas semanalmente). As unidades experimentais foram constituídas por vasos plásticos contendo $8 \mathrm{~L}$ de areia lavada. A lavagem da areia foi feita com uma solução de ácido clorídrico 0,01 $\mathrm{mol} \mathrm{L}^{-1} \mathrm{e}$ água destilada em abundância. A análise química da areia não mostrou presença de B extraído com água quente (Abreu et al., 1994). O delineamento experimental foi em blocos ao acaso, em esquema fatorial $4 \times 2$, com parcelas subdivididas no tempo (semanas de amostragem), com quatro repetições. As sementes foram pré-germinadas em um substrato de areia lavada e vermiculita. Após quatro dias, realizouse $o$ transplantio de duas plântulas para cada unidade experimental, selecionando-se as de tamanhos similares. Além das irrigações normais, todos os vasos receberam, uma vez por semana, solução nutritiva de Hoagland \& Arnon (1950) modificada, seguindo as aplicações com e sem B, cuja fonte foi o ácido bórico. Nas duas primeiras semanas, aplicou-se 1/5 da concentração total dos nutrientes e, nas duas seguintes, metade da concentração. A partir da quinta semana, os vasos receberam solução com concentração completa. A reposição da água transpirada foi feita diariamente, calculando-se a reposição por meio da pesagem dos vasos.

As avaliações iniciaram-se seis semanas após o transplantio, ou seja, uma semana após a aplicação da solução com concentração completa, e foram feitas semanalmente por mais três semanas subsequentes. Ao final de cada semana de avaliação, foram colhidas as plantas inteiras de cada tratamento. Em todas as semanas, as plantas de cada vaso foram colhidas e separadas em folhas, caule (haste principal + pecíolos) e raízes. Na segunda e quarta semanas, as folhas foram subdivididas, de acordo com sua posição na haste principal, em folhas do $1^{\circ}$ e $2^{\circ}$ nós a partir do solo (12 ), $3^{\circ}$ e $4^{\circ}$ nós (3-4), $5^{\circ}$ e $6^{\circ}$ nós (5-6), $7^{\circ}$ e $8^{\circ}$ nós $(7-8)$ e $9^{\circ}$ e $10^{\circ}$ nós (9-10), quando existiam. Essa subdivisão teve como objetivo verificar a mudança do teor e, ou, acúmulo do B no tecido foliar nas diferentes posições da planta durante o período de duas semanas. Após as divisões, os materiais foram lavados e secos em estufa com ventilação forçada a $60^{\circ} \mathrm{C}$ até atingirem peso constante, obtendo-se a massa de matéria seca da parte aérea (folhas + caule) e da raiz. Posteriormente, foi determinado o teor de $\mathrm{B}$ no tecido vegetal, utilizando o método da azometina-H (Malavolta et al., 1997).

As variáveis analisadas foram submetidas à análise de variância (teste F); quando houve diferença significativa entre as variáveis qualitativas, as médias foram comparadas pelo teste de Tukey a $5 \%$, e as variáveis quantitativas foram submetidas à análise de regressão, utilizando o programa estatístico SISVAR 4.2 (Ferreira, 2003).

\section{RESULTADOS E DISCUSSÃO}

\section{Matéria seca e acúmulo de boro}

A matéria seca da parte aérea (MSPA) e da raiz (MSRA), assim como o acúmulo de B na parte aérea (ACUM PA) e na raiz (ACUM RA), foram influenciados significativamente pela cultivar e pela interação doses x semanas (Quadro 1). Entretanto, não foram observadas, com exceção da razão de acúmulo entre parte aérea e raiz, interações das doses de B com as cultivares. Em geral, as cultivares FM 993 e FMT 523 produziram mais matéria seca que FM 910 e FMT 701 (Quadro 2). FM 993 e FMT 701 têm ciclo mais longo que FM 910 e FMT 523, o que talvez justifique a menor produção de matéria seca neste experimento, uma vez que seu desenvolvimento inicial pode ser mais lento em razão do ciclo mais longo. Embora as diferenças não tenham sido sempre significativas, o acúmulo de $\mathrm{B}$ no tecido seguiu a produção de matéria seca. Independentemente do tratamento (com ou sem B), a produção de matéria seca e o acúmulo de $B$ aumentaram no decorrer das semanas. De maneira geral, quando o B foi fornecido, os valores foram superiores (Figura 1); para tratamentos sem B, havia a reserva das sementes e, talvez, algum $B$ residual no substrato.

Com a aplicação de $\mathrm{B}$, as produções de MSPA e MSRA (Figura 1a, c) foram superiores às do tratamento sem B em 109 e $178 \%$, respectivamente, na média das quatro semanas de avaliação. Da primeira para a quarta semana, no tratamento com $\mathrm{B}$, houve aumento de $21 \mathrm{~g}$ na MSPA e $6 \mathrm{~g}$ na MSRA. No tratamento sem B esse aumento foi de apenas $8 \mathrm{~g}$ na MSPA e $1 \mathrm{~g}$ na MSRA. A menor produção de matéria seca no tratamento sem aplicação de B é explicada pela rápida inibição do crescimento, causada pela deficiência desse nutriente (Marschner, 1995). Dessa forma, o efeito negativo da deficiência de $B$ foi maior nas raízes que na parte aérea. Quando em deficiência de $B$, as raízes param de se alongar e é estimulada a ramificação, resultando em baixo crescimento e em raízes excessivamente ramificadas (Rosolem \& Costa, 2000). Em plantas superiores, a resposta mais rápida à deficiência de $\mathrm{B}$ é a inibição do crescimento radicular (Dell \& Huang, 1997) em consequência do efeito do nutriente sobre as auxinas, principalmente o ácido indolacético (Bohnsack \& Albert, 1977).

É interessante notar que a diferença na resposta entre parte aérea e raiz é um aspecto que se acentuou com o decorrer do experimento (Figura 2), pois na ausência de $\mathrm{B}$ a razão entre a produção de matéria 
seca da parte aérea e a da raiz cresce linearmente, ao contrário do que ocorre quando o $\mathrm{B}$ é fornecido na solução nutritiva.

$\mathrm{O}$ acúmulo de $\mathrm{B}$ na parte aérea foi maior em 0,59 mg por vaso $(552 \%)$ com aplicação de B, na média das quatro semanas, em comparação ao tratamento sem B (Figura 1b). Da primeira para a quarta semana, observou-se incremento no ACUM PA de 1,24 e 0,20 $\mathrm{mg}$ por vaso, com e sem aplicação de B, respectivamente.

$\mathrm{O}$ acúmulo de $\mathrm{B}$ na raiz mostrou diferença significativa entre as doses a partir da terceira semana (Figura 1d) e seguiu o mesmo comportamento do acúmulo na parte aérea. A ausência de diferença entre tratamentos nas primeiras semanas (primeira e segunda semanas) pode ser devido às reservas de $B$ encontradas nas sementes. Da primeira para a quarta semana, o valor do ACUM RA aumentou 0,16 e 0,05 $\mathrm{mg}$ por vaso, com e sem aplicação de $B$, respectivamente.
Embora tenha ocorrido diferença no acúmulo de B entre as cultivares, a ausência de interações (Quadro 1) mostra que sua reação ao $B$ foi semelhante, como já havia sido observado por Rosolem et al. (1999) em cultivares mais antigas, como CNPA-ITA 90, IAC 22 e IAC 20.

\section{Acúmulo relativo de boro nos tecidos (folhas, caule e raiz)}

No tratamento que recebeu boro $(+\mathrm{B})$, a quantidade acumulada nas folhas variou de 51 a $60 \%$, no caule, de 15 a $26 \%$, e na raiz, de 15 a $34 \%$, do total de B acumulado na planta (Figura 3). Na ausência da aplicação de $\mathrm{B}$, a percentagem do nutriente acumulado nas folhas foi menor, variando de 19 a $48 \%$, ao passo que no caule e na raiz a percentagem foi maior do que no tratamento que recebeu o nutriente e variou de 17 a $36 \%$ e de 30 a $63 \%$ do total de B acumulado nas plantas, respectivamente. Esses dados estão de acordo com os encontrados por Zhao \&

Quadro 1. Nível de probabilidade de significância do teste F para a ANOVA dos resultados de matéria seca da parte aérea (PA) e raiz (RA) e do acúmulo de boro na parte aérea (PA) e raiz (RA), de cultivares de algodoeiro em função da aplicação de boro, em avaliações realizadas durante quatro semanas

\begin{tabular}{|c|c|c|c|c|c|c|c|}
\hline \multirow{2}{*}{$\begin{array}{l}\text { Causa de } \\
\text { Variação }\end{array}$} & \multicolumn{4}{|c|}{ Matéria Seca } & \multicolumn{3}{|c|}{ Acúmulo } \\
\hline & PA & $\mathbf{R A}$ & Total & PA/RA & PA & RA & Total \\
\hline & & & & $\mathrm{P}>\mathrm{F}$ & & & \\
\hline Blocos & 0,312 & 0,655 & 0,381 & 0,731 & 0,285 & 0,161 & 0,218 \\
\hline $\operatorname{Doses}(\mathrm{D})$ & $<0,000$ & $<0,000$ & $<0,000$ & $<0,000$ & $<0,000$ & $<0,000$ & $<0,000$ \\
\hline Cultivares(C) & 0,001 & 0,000 & 0,001 & 0,005 & 0,047 & 0,000 & 0,010 \\
\hline $\operatorname{Semanas}(\mathrm{S})$ & $<0,000$ & $<0,000$ & $<0,000$ & $<0,000$ & $<0,000$ & $<0,000$ & $<0,000$ \\
\hline $\mathrm{DxC}$ & 0,629 & 0,224 & 0,479 & 0,021 & 0,507 & 0,181 & 0,390 \\
\hline DxS & $<0,000$ & $<0,000$ & $<0,000$ & 0,001 & $<0,000$ & $<0,000$ & $<0,000$ \\
\hline $\mathrm{CxS}$ & 0,714 & 0,682 & 0,761 & 0,583 & 0,735 & 0,138 & 0,814 \\
\hline $\mathrm{DxCxS}$ & 0,605 & 0,250 & 0,501 & 0,104 & 0,779 & 0,466 & 0,861 \\
\hline
\end{tabular}

Quadro 2. Matéria seca da parte aérea (MSPA) e raiz (MSRA) e acúmulo de boro na parte aérea (ACUM PA) e raiz (ACUM RA) em algodoeiro

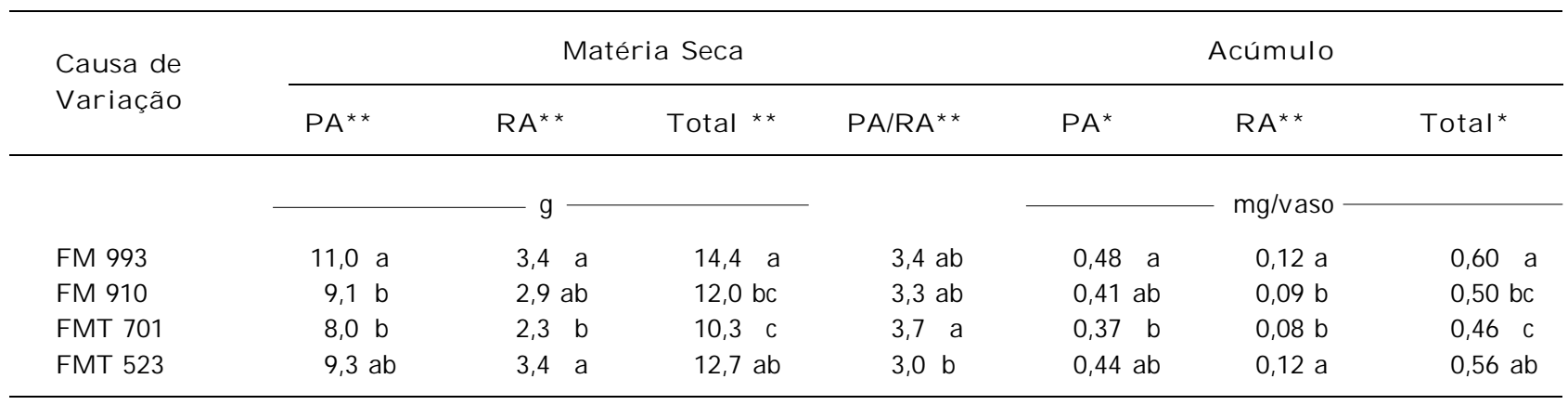

Médias seguidas por letras distintas nas colunas diferem entre os cultivares pelo teste de Tukey a $5 \%(*)$ e $1 \%(* *)$. 
Oosterhuis (2002), trabalhando também com deficiência de B em algodão.

Dannel et al. (2000) observaram maior teor de B em raízes de girassol cultivado sob deficiência e inferiram que o baixo fornecimento de B estimula a sua absorção e, sob suprimentos mais altos, a absorção segue uma cinética linear de não saturação. Dessa forma, a absorção ocorre por meio de dois processos:
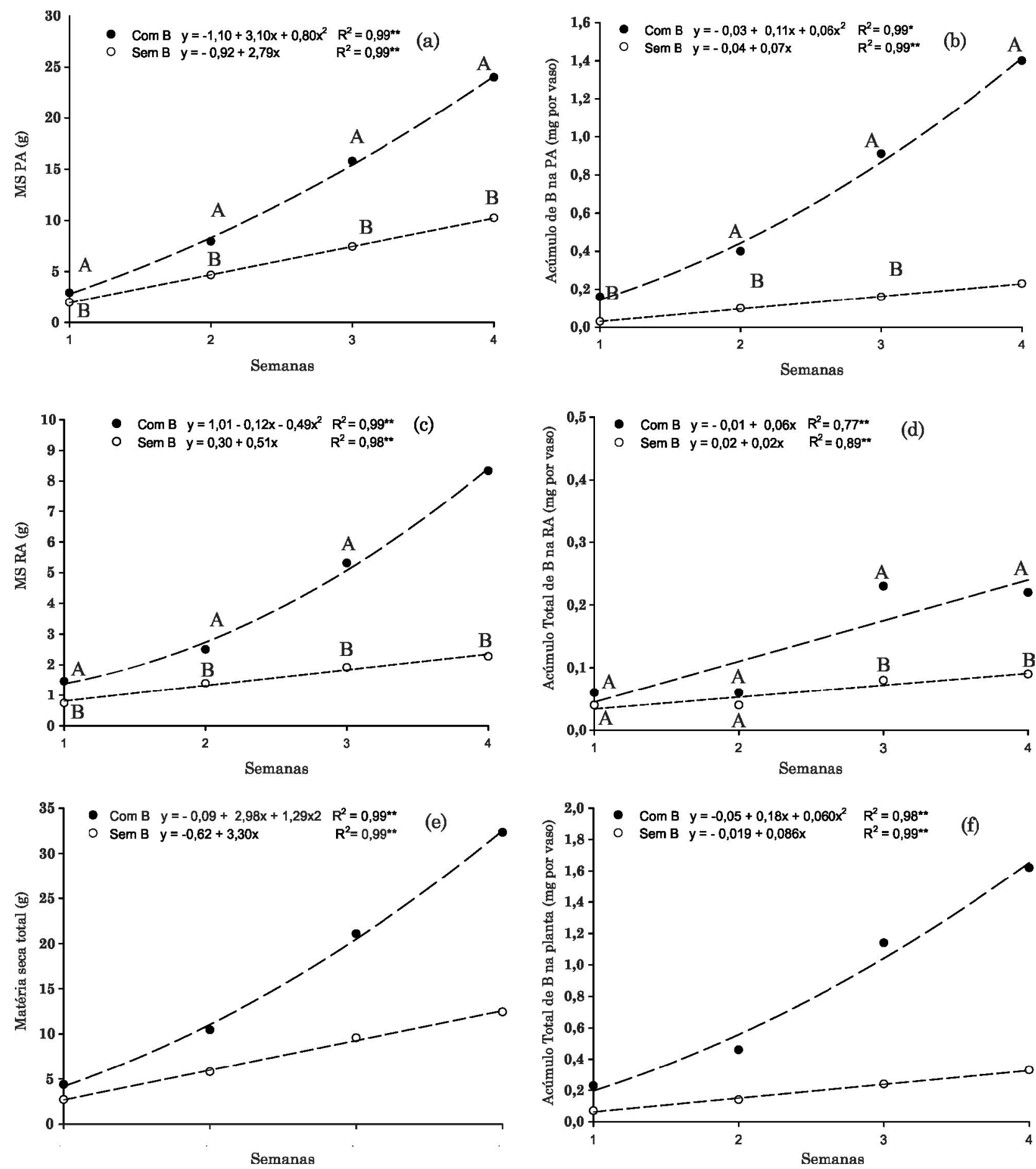

Figura 1. Matéria seca da parte aérea (a), acúmulo de boro na parte aérea (b), matéria seca da raiz (c), acúmulo de boro da raiz (d), matéria seca total (e) e acúmulo total de boro na planta (f) em algodoeiro, em função do tempo e da adição de $B$ à solução nutritiva (média de quatro cultivares). * $\mathbf{e} * *$ indicam significância ( $p<0,05$ e p $<0,01$, respectivamente). Letras distintas indicam diferença significativa entre doses, dentro de cada semana $(p<0,05)$. Os gráficos estão apresentados em escalas diferentes. 
um transporte mediado por um carregador saturável a baixas concentrações, ou seja, Vmáx e Km baixos, indicando alta afinidade pelo transportador, e um processo regido por difusão, não saturável, em concentrações mais altas, ou seja, Vmáx e Km altos. Assim, pode-se inferir que em baixas concentrações de $\mathrm{B}$ a distribuição do nutriente da raiz para a parte aérea foi dificultada, uma vez que todo o nutriente presente no meio foi utilizado na própria raiz; entretanto, quando o nutriente foi fornecido na solução nutritiva, o processo de absorção passiva não foi saturado e, assim, foram observadas quantidades e proporções mais elevadas de B na parte aérea, principalmente nas folhas (Figura 3).

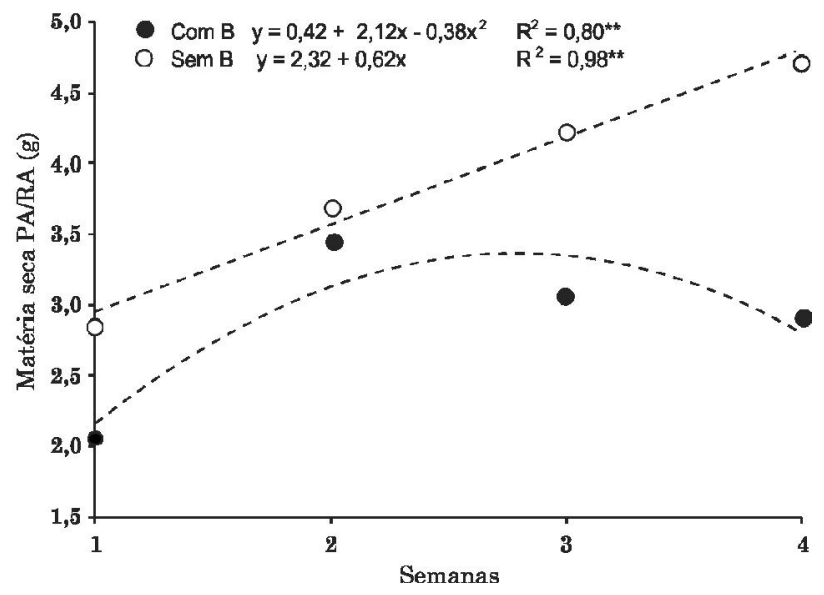

Figura 2. Relação entre a produção de matéria seca da parte aérea e raiz de algodoeiro, em função de doses de $B$ e do tempo de exposição à deficiência (média de quatro cultivares). ** indica significância $(p<0,01)$.

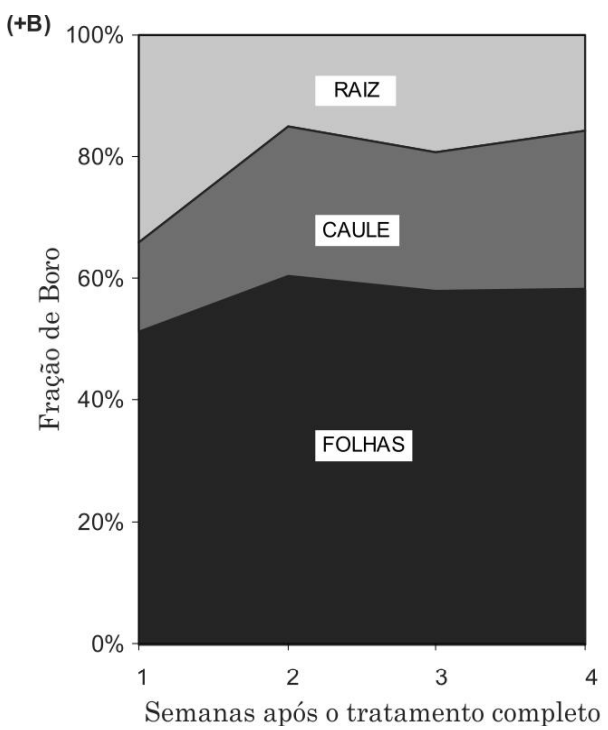

\section{Teor e acúmulo de boro nas folhas entre os nós da haste principal}

O teor de B nas folhas entre os diferentes nós da haste principal (Figura 4a) decresceu da parte inferior para a superior da copa, no tratamento com aplicação de B na segunda e quarta semanas. Considerando a folha da mesma posição do nó e avaliando a variação entre as semanas, percebe-se que o teor de B aumenta no decorrer do tempo quando ele é fornecido, porém, na ausência da aplicação desse nutriente, seu teor decresceu da segunda para a quarta semana nas folhas dos nós 5-6 e 7-8. Essa redução pode ser atribuída ao efeito de diluição causado pelo aumento da matéria seca dessas folhas (Figura 5).

As evidências dessa diluição confirmam-se quando se observa o acúmulo de $\mathrm{B}$ no tratamento sem esse nutriente (Figura $4 \mathrm{~b}$ ), que se mantém praticamente o mesmo nas folhas dos nós 5-6 da segunda (0,03 mg por vaso) para a quarta semana (0,02 mg por vaso) e mostra incremento nas folhas dos nós 7-8 (0,004 para 0,034 mg/vaso). Se a diminuição do teor de B nas folhas dos nós 5-6 e 7-8 fosse uma evidência de redistribuição para as folhas mais novas (folhas dos nós 9-10) presentes na planta na quarta semana, seria observado também decréscimo no acúmulo de $\mathrm{B}$ destas folhas da segunda para a quarta semana.

A concentração de $B$ em folhas de idades diferentes pode fornecer evidência da mobilidade do nutriente. A ocorrência de teores maiores de $\mathrm{B}$ em folhas velhas ou maduras é uma indicação de imobilidade do nutriente, enquanto teores mais altos em folhas mais jovens são uma indicação da mobilidade, uma vez que essas folhas transpiram menos que as folhas mais velhas (Brown \& Shelp, 1997).

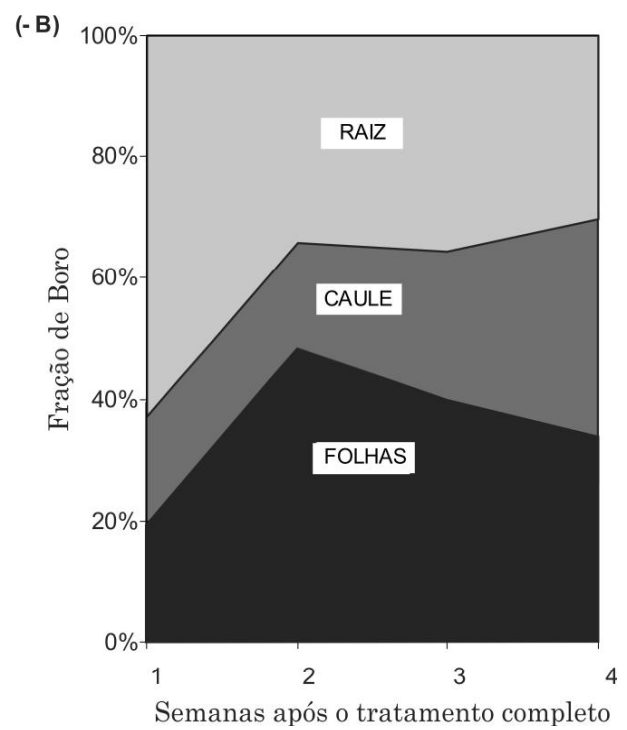

Figura 3. Percentagem de distribuição do B acumulado nos tecidos vegetais (folhas, caule e raiz) de cultivares de algodão com boro (+B) e sem boro (-B), nas quatro semanas de avaliação (média de quatro cultivares). 

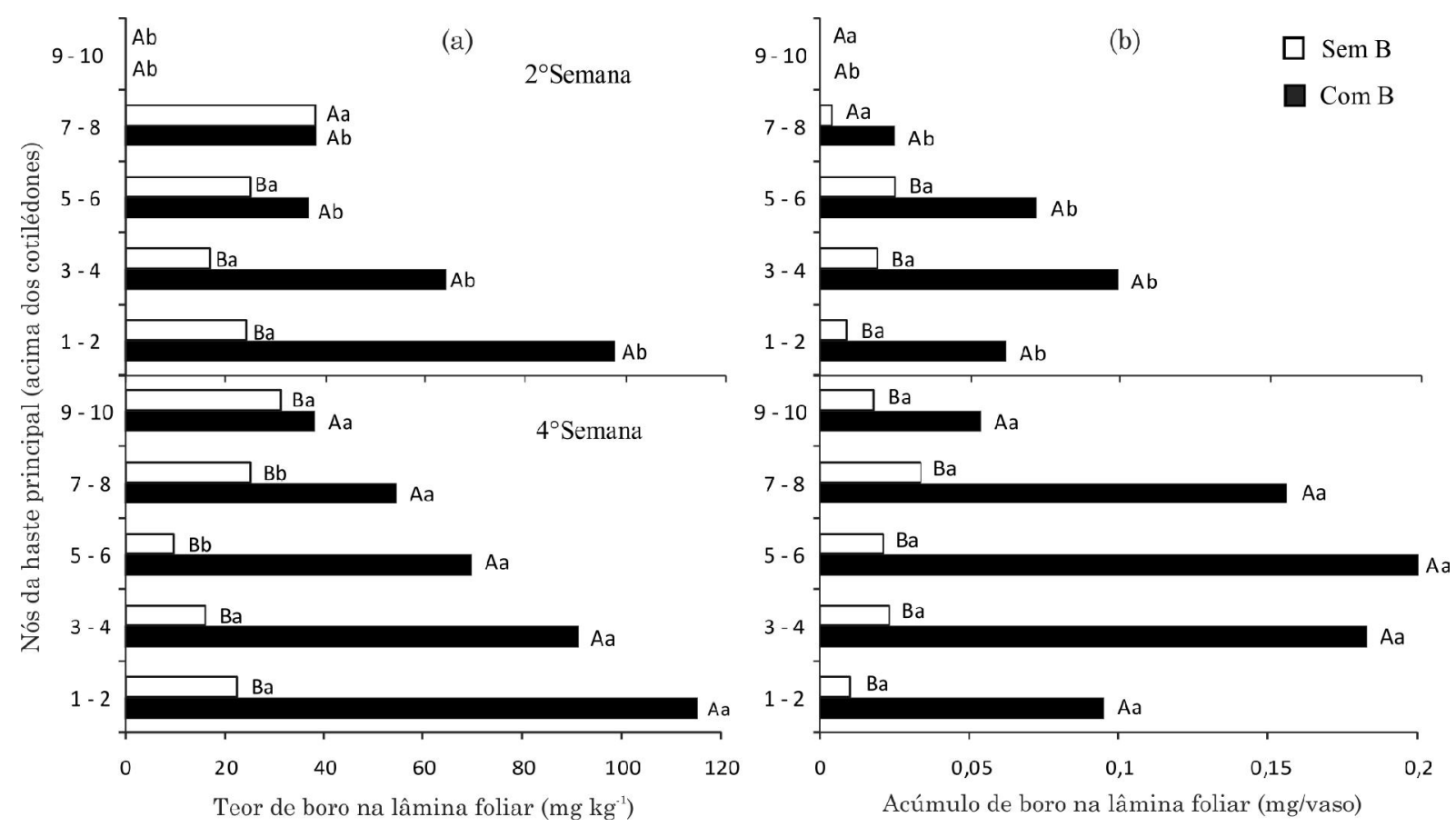

Figura 4. Teor (a) e acúmulo (b) de boro nas folhas de diferentes nós da haste principal, na segunda e quarta semanas de avaliação, em cultivares de algodoeiro com e sem boro (média de quatro cultivares). Letras maiúsculas distintas indicam diferença significativa entre doses na mesma semana, e minúsculas indicam diferença significativa entre semanas, na mesma dose $(p<0,05)$.

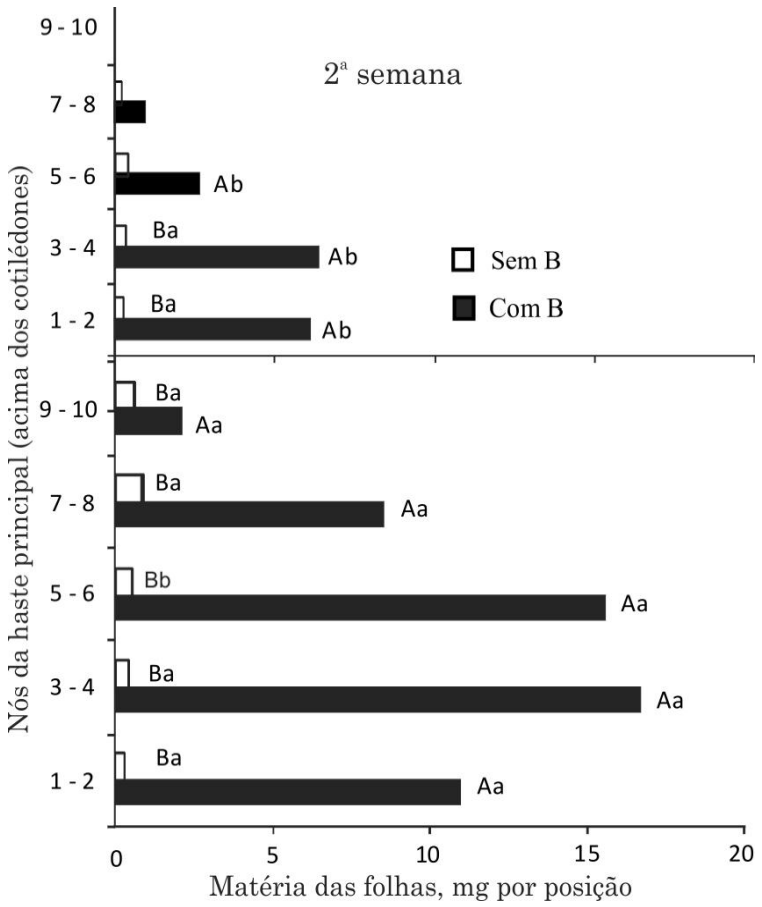

Figura 5. Matéria seca de folhas de diferentes nós da haste principal, na segunda e quarta semanas de avaliação, em cultivares de algodoeiro com e sem boro (média de quatro cultivares). Letras maiúsculas distintas indicam diferença significativa entre doses na mesma semana, e minúsculas indicam diferença significativa entre semanas, na mesma dose $(p<0,05)$.
O aumento do acúmulo nas folhas dos nós 7-8 e 910 das plantas cultivadas com adição de B (Figura 4b) pode ser devido ao aumento da matéria seca destas folhas, já que o acúmulo é resultante do teor e da matéria seca produzida. É importante ressaltar que no tratamento sem aplicação de B a quantidade do nutriente encontrada nas folhas é, possivelmente, originada dos cotilédones.

\section{CONCLUSÕES}

1. A ordem de acúmulo de B pelas cultivares de algodão seguiu a ordem de acúmulo de matéria seca.

2. Não houve evidências de translocação de B em algodoeiro, e a resposta ao nutriente foi semelhante entre as cultivares.

3. Em plantas não deficientes em $\mathrm{B}$, mais de $50 \%$ do nutriente encontra-se nas folhas, mas, em situação de deficiência, o B é encontrado em maior proporção nas raízes e no caule.

\section{LITERATURA CITADA}

ABREU, C.A.; ABREU, M.F.; RAIJ, B. van; BATAGLIA, O.C. \& ANDRADE, J.C. Extraction of boron from soil by microwave heating for ICP-AES determination. Comm. Soil Sci. Plant Anal., 25:3311-3333, 1994. 
BLEVINS, D.G. More hidden hunger: Special nutrient needs of plants based on their structure and function. In: INTERNATIONAL PLANT NUTRITION COLLOQUIUM, 16., 2009, Davis. Proceedings...: Davis, 2009. Disponível em: <http://escholarship.org/uc/item/ $7 \mathrm{pz} 1 \mathrm{~g} 68 \mathrm{~s}>$.

BROWN, P.H. \& SHELP, B.J. Boron mobility in plants. In: DELL, B.; BROWN, P.H. \& BELL, R.W., eds. Boron in soils and plants. Dordrecht, Kluwer Academic Publishers, 1997. p. 85-101.

BOHNSACK, C.W. \& ALBERT, L.S. Early effects of boron deficiency on indolacetic acid oxidase levels of squash root tips. Plant Physiol., 59:1047-1050, 1977.

CARVALHO, M.C.S.; FERREIRA, G.B. \& STAUT, L.A. Nutrição, calagem e adubação do algodoeiro. In: FREIRE, E. C., ed. Algodão no cerrado do Brasil. Brasília, ABRAPA, 2007. 918p.

DANNEL, F.; PFEFFER, H. \& RÖMHELD, V. Characterization of root boron pools, boron uptake and boron translocation in sunflower using the stable isotopes ${ }^{10} \mathrm{~B}$ and ${ }^{11} \mathrm{~B}$. Austr. J. Plant Physiol., 27:397$405,2000$.

DELL, B. \& HUANG, L. Physiologic response of plants to low boron. Plant Soil, 193:103-120, 1997.

FERREIRA, D.F. SISVAR 4.2. Sistema de análises estatísticas. Lavras, Universidade Federal de Lavras, 2003.

FONTES, R.L.F.; MEDEIROS, J.F.; NEVES, J.C.L.; CARVALHO, O.S. \& MEDEIROS, J.C. Growth of brazilian cotton cultivars in response to soil applied boron. J. Plant Nutr., 31: 902-918, 2008.

HOAGLAND, D.R. \& ARNON, I. The water culture method for growing plants without soil. California, Agriculture Experimental Station, 1950. p.32. (Circular, 347).

LOESCHER, W.H.; EVERARD, J.D.; CANTINI, C. \& GRUMET, R. Sugar alcohol metabolism in source leaves. In: MADORE, M.A. \& LUCAS, W.J., eds. Carbon partitioning and source sink interactions in plants: Current topics in plant physiology. Am. Soc. Plant Physiol. Series, 13:170179, 1995.
MALAVOLTA, E.; VITTI, G.C. \& OLIVEIRA, S.A. Avaliação do estado nutricional de plantas: princípios e aplicações. Piracicaba, Potafós, 1997. 308p.

MARSCHNER, H. Mineral nutrition of higher plants. Londres: Academic Press, 1995. 889p.

OLIVEIRA, R.H.; MILANEZE, R.S.D.; MORAES-DALLAQUA, M.A. \& ROSOLEM, C.A. Boron deficiency inhibits petiole and peduncle cell development and reduces growth of cotton. J. Plant Nutr., 29:2035-2048, 2006.

RERKASEM, B. Boron nutrition of crops and genotypic variation in boron effciency. In: GOLDBACH, H.E.; RERKASEM, B.; WIMMER, M.A.; BROWN, P.H.; THELLIER, M. \& BELL, R.W., eds. Boron in plant and animal nutrition. Dordrecht, Kluwer Academic/Plenum Publishers, USA, 2002. 410p.

ROCHESTER, I. Nutrient uptake and export from an Australian cotton field. Nutr. Cycl. Agroecosyst., 77:213-223, 2007.

ROSOLEM, C.A. \& COSTA, A. Cotton growth and boron distribution in the plants as affected by a temporary deficiency of boron. J. Plant Nutr., 23:815-825, 2000.

ROSOLEM, C.A.; QUAGGIO, J.A. \& SILVA, N.M. Algodão, amendoim e soja. In: FERREIRA, M.E.; CRUZ, M.C.P.; RAIJ, B. van \& ABREU, C.A., eds. Micronutrientes e elementos tóxicos na agricultura. Jaboticabal, CNPq/ FAPESP/POTAFOS, 2001. p.321-354.

ROSOLEM, C.A.; ESTEVES, J.A.F. \& FERELLI, L. Resposta de cultivares de algodoeiro ao boro em solução nutritiva. Sci. Agric., 56:705-711, 1999.

SATYA, S.; PITCHAI, J.G. \& INDIRANI, R. Boron nutrition of crops in relation to yield and quality - A review. Agric. Rev., 30:139-144, 2009.

TANAKA, M. \& FUJIWARA, T. Physiological roles and transport mechanisms of boron: perspectives from plants. Eur. J. Physiol., 456:671-677, 2008.

ZHAO, D. \& OOSTERHUIS, D.M. Cotton carbon exchange, nonstructural carbohydrates, and boron distribution in tissues during development of boron deficiency. Field Crops Res., 78:75-87, 2002. 